University of Nebraska - Lincoln

DigitalCommons@University of Nebraska - Lincoln

Faculty Publications, Department of Psychology

Psychology, Department of

2008

\title{
Individual Decision Making and the Evolutionary Roots of Institutions
}

\author{
Richard McElreath \\ University of California - Davis, mcelreath@ucdavis.edu \\ Robert Boyd \\ University of California - Los Angeles, rboyd@anthro.ucla.edu \\ Gerd Gigerenzer \\ Max Plank Institute for Human Development, sekgigerenzer@mpib-berlin.mpg.de \\ Andreas Glöckner \\ Max Plank Institute for Research on Collective Goods, gloeckner@coll.mpg.de \\ Peter Hammerstein \\ Humboldt University, Berlin, p.hammerstein@biologie.hu-berlin.de \\ See next page for additional authors
}

Follow this and additional works at: https://digitalcommons.unl.edu/psychfacpub

Part of the Psychiatry and Psychology Commons

McElreath, Richard; Boyd, Robert; Gigerenzer, Gerd; Glöckner, Andreas; Hammerstein, Peter; Kurzban, Robert; Magen, Stefan; Richerson, Peter J.; Robson, Arthur; and Stevens, Jeffrey R., "Individual Decision Making and the Evolutionary Roots of Institutions" (2008). Faculty Publications, Department of Psychology. 524.

https://digitalcommons.unl.edu/psychfacpub/524

This Article is brought to you for free and open access by the Psychology, Department of at DigitalCommons@University of Nebraska - Lincoln. It has been accepted for inclusion in Faculty Publications, Department of Psychology by an authorized administrator of DigitalCommons@University of Nebraska - Lincoln. 


\section{Authors}

Richard McElreath, Robert Boyd, Gerd Gigerenzer, Andreas Glöckner, Peter Hammerstein, Robert Kurzban, Stefan Magen, Peter J. Richerson, Arthur Robson, and Jeffrey R. Stevens 


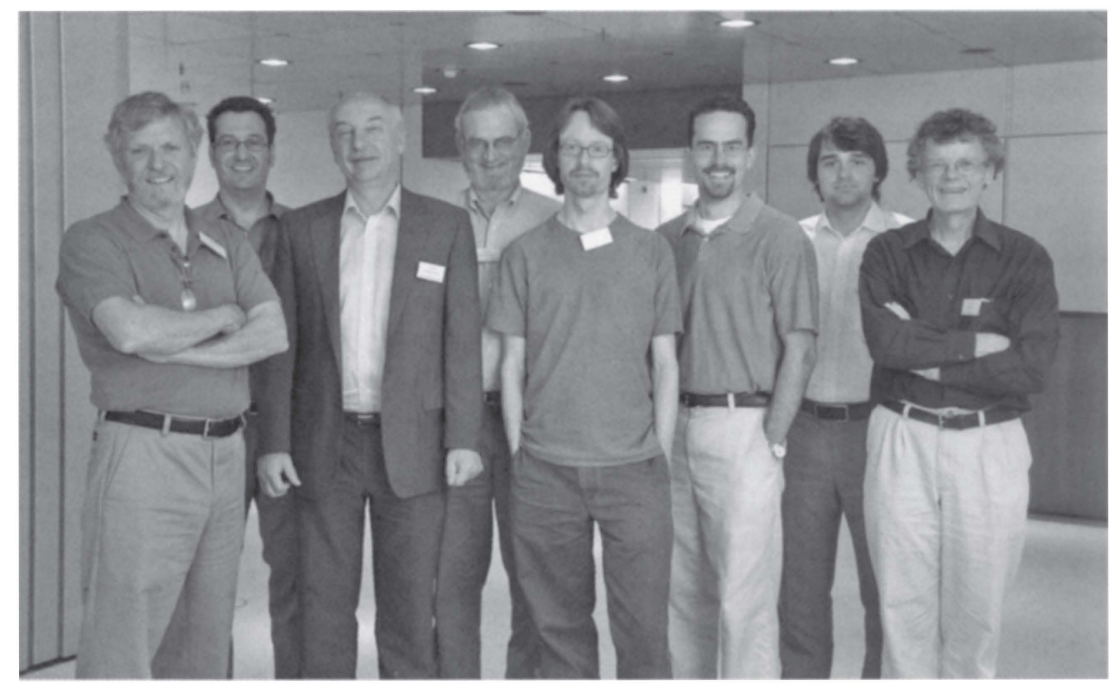

Left to right: Rob Boyd, Stefan Magen, Gerd Gigerenzer, Pete Richerson, Richard McElreath, Jeff Stevens, Andreas Glöckner, Arthur Robson

Published in BETTER THAN CONSCIOUS? DECISION MAKING, THE HUMAN MIND, AND IMPLICATIONS FOR INSTITUTIONS, ed. Christoph Engel and Wolf Singer (Cambridge, MA: The MIT Press, 2008), pp. 325-342. Copyright 2008 Massachusetts Institute of Technology \& the Frankfurt Institute for Advanced Studies. Used by permission. 


\title{
15
}

\section{Individual Decision Making and the Evolutionary Roots of Institutions}

\author{
Richard McElreath, Rapporteur \\ Robert Boyd, Gerd Gigerenzer, Andreas Glöckner, \\ Peter Hammerstein, Robert Kurzban, Stefan Magen, \\ Peter J. Richerson, Arthur Robson, and Jeffrey R. Stevens
}

\section{Introduction}

Humans hunt and kill many different species of animals, but whales are our biggest prey. In the North Atlantic, a male long-finned pilot whale (Globicephala melaena), a large relative of the dolphins, can grow as large as 6.5 meters and weigh as much as 2.5 tons. As whales go, these are not particularly large, but there are more than 750,000 pilot whales in the North Atlantic, traveling in groups, "pods," that range from just a few individuals to a thousand or more. Each pod is led by an individual known as the "pilot," who appears to set the course of travel for the rest of the group.

This pilot is both an asset and a weakness to the pod. The average pilot whale will yield about a half ton of meat and blubber, and North Atlantic societies including Ireland, Iceland, and the Shetlands used to manipulate the pilot to drive the entire pod ashore. In the Faroe Islands, a group of 18 grassy rocks due north of Scotland, pilot whale hunts have continued for the last 1200 years, at least. The permanent residents of these islands, the Faroese, previously killed an average of 900 whales each year, yielding about 500 tons of meat and fat that was consumed by local residents. Hunts have declined in recent years. From 2001 to 2005 , about 3400 whales were killed, yielding about 890 metric tons of blubber and 990 metric tons of meat.

The whale kill, or grindadráp in the Faroese language, begins when a fishing boat spots a pod close enough to a suitable shore, on a suitably clear day. A single boat, or even a small group of fishermen, is not sufficient to trap a 
pod in a fjord, so the first step is to recruit more vessels. In ancient times, a signal fire was lit atop the boat and elected whale marshalls and sheriffs on the land lit bonfires to signal whale marshalls on neighboring islands. Nowadays, mobile phones have proven to be more efficient. As more boats join the hunt, men gather equipment and station themselves on the beach. The boats enclose the pod in a semicircle, driving them ashore. As the pod follows their pilot onto land, the men there kill each whale with one or two cuts through the spine, using specially sharpened knives. Sometimes the pilot will not be driven to land, in which case-according to custom-the pod must be driven back out to sea and allowed to escape.

Shares called skinn, a traditional unit of about 34 kilograms of blubber and 38 kilograms of meat, are distributed via a long-standing system of property rights. Roman numerals are assigned to each whale, and numerals are assigned to those who have rights based upon both residence and participation in the grindadráp. Skinn are cut from these whales, carried home, and the local sheriff ensures that the beach is clean within 24 hours.

The grindadráp is an example of what many call an "institution"- a term that is used in various ways across the human sciences. Sometimes, it indicates modern, formal organizations, like firms and parliaments. Other times it refers to any shared set of understandings, such as "kinship" or "childhood." In this chapter, we use the term to refer to locally stable, widely shared rules that regulate social interaction. This is not a claim about the nature of all things social scientists call "institutions." Rather it is meant to be a practical operationalization of a complex, multifaceted phenomenon.

The grindadráp, like many human institutions, recruits and coordinates human labor, regulating each stage of the event. It has evolved over hundreds of years, both changing and remaining stable as population, economy, and technology have evolved in the islands. The details of this story, however, as is the case for most institutions, are poorly understood. Do the regulations defining the grindadráp function well, or would alternative regulations do better? If the latter, why have those alternatives not evolved? How did the specific rules come to be, and is there any meaningful fit between the structure of human cognition-both in the physiological details and decision processes-and the structure of the institution? We cannot yet construct a widely believed story to explain the specific design of any reasonably complex institution nor for the diversity of institutional forms among human societies.

Just as many aspects of individual decisions are sometimes called "unconscious" or "automatic," we know that some institutions have evolved through "unconscious," nondeliberative mechanisms. Their function can also be largely nondeliberative, as in the case of some institutions that may structure behavior without requiring any reflection on the part of the participants. On the other hand, political institutions exist for the purpose of bringing deliberative mechanisms to bear on institutions in the hope of changing them for the better. The immense project of building an integrated explanation of institutions- 
from individual brains to nations--has only barely begun. In this chapter, we report on our discussions that attempted to sketch the mechanisms that connect individuals to large-scale institutions. We begin with a discussion of current thought on the design of individual decision making. If institutions regulate behavior, then presumably the mechanisms that have evolved to produce individual behavior will be relevant to the broader enterprise of integrating these two scales of explanation. Then we explore ways in which institutions may have evolved, both as a result of individual decision making and as a result of processes distinct from those that govern individual behavior. We approach this topic from two perspectives. Seen one way, unconscious psychological forces constrain the design of institutions, sometimes powerfully. Seen another way, unconscious population-level processes create functional institutional design that few social architects could conceive of with their individual deliberate faculties.

\section{Evolution of Individual Decisions}

In the first half of the 20th century, most biologists thought about the evolution of decisions and learning in terms of selection for general intelligence. A number of key experiments, including demonstration of cue-specific learning in rats (Garcia and Koelling 1966), convinced most that the general intelligence approach was mistaken. As biology textbooks now argue, we understand how natural selection designs cognition by understanding the characteristic problems that each different organism faces.

For example, both birds and mammals use some form of association learning to identify and avoid toxic food. Reinforcement, however, is sometimes specific to the nature of the cues. Birds remember the color of distasteful food, whereas rats remember odor, even when the experimenter associates toxicity with only one or the other. If color, rats do not learn to avoid the poison. If odor, birds have a similar problem. A usual interpretation of this result is that birds forage from a distance in daylight, where color is the first available cue, while rats forage in the dark, where color is unavailable or unreliable. Even among different bird species, association learning varies in efficacy, depending upon the ecological details (Balda et al. 1997).

Biologists have come to expect most organisms to be good at ecologically relevant problems, rather than simply to differ in general problem-solving ability. Sometimes this specificity of ability is discovered in animals people tend to regard as rather dim (e.g., birds). Recent experiments by Nicola Clayton and her coworkers show that humans are not the only animals that plan for the future (Raby et al. 2007). It had previously been thought that while humans can represent future needs and act accordingly, provisions for the future observed in other animals resulted from either fixed action patterns or current motivational states. Clayton and her coworkers experimented with the Western Scrub 
Jay, a species that caches food. The jays were housed in three rooms, call them A, B, and C. Sometimes they spent the night in room A, while other times in B. Experiments manipulated how they were fed in different rooms in the morning. For example, in one experiment, when they spent the night in A, they received no breakfast. If they slept instead in room $B$, they did receive breakfast. During the previous afternoon, birds were given an opportunity to cache in either room, and then one of the rooms was chosen at random and they spent the night in that room. The jays cached food preferentially in room A, perhaps anticipating that they would be hungry the next morning. This decision was independent of whether they were hungry or satiated in the afternoon.

Despite cases such as this one, there are reasons to consider that some decision mechanisms may be quite general across behavioral domains. Such a view is more common in the human sciences, and there are different routes to this opinion. First, experiments such as those that illustrate learning differences in birds and rats demonstrate only specificity of cues. The ways in which cues are processed may be quite similar. Some evolutionary psychologists argue that human reasoning comprises many special-purpose cognitive mechanisms (Cosmides and Tooby 1992), and yet some of their favorite examples demonstrate only specificity of cues, not of processing. For example, the Wason selection task shows that people make different selections when the task is framed in one of two ways (they receive alternative cues), but the core information remains unchanged (for further discussion, see chapters by Stevens and Schooler, both this volume). Different cues may activate different processing algorithms. The reasoning employed in either case, however, may be employed routinely in other contexts. The experiments do not address this question.

Another reason to consider some generality of processing is to account for the findings that decision behavior in animals (e.g., Real 1991) and humans (e.g., Kahneman and Tversky 1972) can sometimes be predicted by weightedadditive integration of information. Single-strategy models may also be frugal, in a way, by avoiding the problem of a meta-decision to select between different specific cognitive strategies. Glöckner (this volume) suggests a very general decision model—consistency maximizing by parallel constraint satisfaction - which he thinks can account for many findings in the field. According to the model, decision making is based on mental representations of the decision tasks that are formed by automatic processes. In every decision task, these processes, which have evolved from processes of perception, modify the information and form consistent mental representations (i.e., interpretations). Parts of these mental representations enter awareness and lead to decisions. The amount of information provided as input to the algorithm may vary tremendously, and the sensory modalities in each case may be distinct. However, if the mental representation reflects the structure of the environment properly, it necessarily produces good decisions in all possible contexts. From the perspective of the model, there are no distinct decision strategies; there are only distinct ways of looking for information and structuring the mental 
representation of the decision task. From such a perspective, any simplifying heuristic is a completely nested model to the network model. Perhaps redundancy of processing, but also variation in input and information structuring could be an efficient adaptive design.

Others, in the bounded rationality tradition of Herbert Simon, criticize the view that there can be any single robust decision algorithm (Gigerenzer et al. 1999). Flexible decision models, just like regression in statistics, can indeed be fit to many contexts. This fitting, however, has drawbacks. First, the parameters have to be fit by some process, whether learning or evolution. If this process takes place over behavioral time (learning), then the goodness of fit will be limited to those contexts sufficiently sampled behaviorally. For complex contexts with many states to sample over, either the organism makes do with a small sample, and risks over-fitting, or pays large costs of learning. Over-fitting occurs when a parameter-rich model is trained on too little information. Unless parameters can be estimated sufficiently well, an organism (just like a statistician) can actually make more accurate predictions by considering less information (Gigerenzer et al. 1999; also, for an accessible introduction to over-fitting, see Forster and Sober 1994). For some learning problems, no cost will be enough, because the problem is combinatorially hard enough that the organism (if not the solar system) will be dead before enough sampling or calculation is completed. If the organism uses a general, parameter-rich mechanism, the organism will be stuck over-fitting. If the fitting process is evolution through natural selection, then the individual's lifespan is not the problem, but individual organisms will not be able to respond to novel contexts adaptively. In long-lived organisms in variable environments, like ourselves, the costs of rigid innate fits might be quite high. This is due to another kind of over-fitting, this time as a result of the nonstationary nature of the environment.

An alternative to models that require a lot of fitting is to have simple heuristics that can be combined and employed in specific contexts (Gigerenzer et al. 1999). These mechanisms avoid over-fitting by having few, if any, adjustable parameters. In out-of-sample prediction tests, such heuristics often win soundly over more information-rich strategies. However, heuristics err on bias, where parameter-rich models err on variance. Their success depends upon being properly selected for the appropriate decision context and information environment. This requires a hierarchy of heuristics, or perhaps "meta-heuristics." This requirement begs additional questions, of course. There is a healthy theoretical and experimental literature comparing simple heuristics to complex learning models (see, e.g., Bröder and Schiffer 2003; Bergert and Nosofsky 2007). We expect this debate over the generality and complexity of decision mechanisms to continue for some time.

Another argument sometimes offered for expecting special-purpose cognitive mechanisms is via the analogy to organs (Tooby and Cosmides 1992). Kidneys, hearts, lungs, and livers are functionally discrete, localized adaptations to different physiological challenges. The discovery of potentially similar 
localization of function in the brain, with Wernicke's and Broca's language areas, led to speculation that much of the brain exhibited functional specialization, instead of general mechanisms. This is suggestive analogizing, but some evolutionary logic is needed to put this on solid scientific footing. If there are good functional reasons for less-specialized mechanisms, they do appear to evolve. The immune system, for example, contains a broad learning system, that generates variation and selective retention. An alternative would be to have specialized immune modules for different diseases, yet given how pathogens evolve, a learning immune system better fulfills the functional needs of the organism.

Evidence suggests that selection does sometimes favor "general" intelligence. Humans aside, some evidence from the field suggests that brain size in primates and birds is correlated with rather general increases in problem-solving abilities. Reader and Laland (2002) found that field reports of innovation, social learning, and tool use correlated with the species' executive brain size. Sol et al. (2005) found that birds from groups with larger brains established more successfully in novel environments and that they did so by generating novel adaptive behaviors.

\section{How Does Selection Design Mechanism?}

There are many ways to make a clock (see Schooler, this volume). Chinese water clocks function by converting a continuous process of pouring water into a periodic process of emptying full buckets. Pendulum clocks use wave momentum, and modern quartz clocks exploit the vibrations of tiny crystals, when exposed to current. The surface "behavior" of each of these mechanisms is similar, yet the details are distinct, and the differences matter for cost and accuracy.

Similarly, evolved decision-making mechanisms can be considered at both algorithmic and implementation levels (Schooler, this volume). The algorithmic level of abstraction refers to the crude grammar of how information (cues) is translated into a decision (or output signal). The implementation level refers to the details of the machinery. These two levels do not map necessarily directly onto one another. For example, both humans and bees can learn by reinforcement, in some contexts. However, the last common ancestor of these species, the urbilaterian, had a very simple brain. Bees and humans likely implement reinforcement using quite different neural architectures. Granted, if we specify algorithms, sufficiently precisely, even very similar information processes will appear different. However, at the level of abstraction of much work in modeling cognition, we suspect this distinction is of value.

This distinction is important for our purposes because there are reasons to believe that natural selection may leave many aspects of implementation unspecified. In the case of protein evolution, a similar phenomenon is well understood. Many different sequences of DNA yield identical, or functionally 
identical, chains of amino acids (proteins). Neutral mutation can tinker with the sequence harmlessly for long periods of evolutionary time. Eventually, the sequences drift close enough to a change such that the function of the protein is drastically altered. Then one mutation will cause a sudden shift in function, with important consequences. Different lineages, however, will have functionally identical proteins, but very different underlying sequences.

If cognitive evolution bears any resemblance, then it may be quite hard to make good predictions about implementation, given function and algorithm. At the scale of decision mechanisms, we might expect variation in the underlying implementation, because organic evolution is path dependent: there are multiple ways to build an organ or algorithm, and one may be better than all others, but the organism cannot get there from where it is.

Once more is known about the fine structure of cognition, it will turn out that local optima and path dependency broadly stabilize diversity in implementation of decision making, as well.

\section{Implementation Costs}

Another reason to be pessimistic about our ability to deduce accurately or infer implementation from algorithms is the difficulty of specifying correctly the costs of alternative implementations. This is not always true: evolutionary biologists who study flight have powerful principles derived from aerodynamics that allow them to make educated guesses at marginal costs of variations in wing shape and muscle attachment. These systems are also conducive to experimentation. Together, this has allowed them to explain variation in wing design among birds, as well as why insect wings are both so different from bird wings and from one another (Alexander 2002; Dudley 2002).

There have been important attempts to quantify costs of alternative decision algorithms, such as the widely cited analyses of Payne, Bettman, and Johnson (1993). In neuroscience, however, we know of no easy-or at least agreed upon-way to infer the differential costs, in evolutionary terms, of alternative implementations. We may be able to make profitable guesses, but these would not be derived from any engineering knowledge of the brain. There are hints, however, that it is possible to estimate some potentially fitness-relevant metabolic costs. In a recent set of studies, Gailliot et al. (2007) provided some evidence about the metabolic costs associated with "hard" mental processes. In particular, they looked at tasks that required "self-control." In one case, subjects were shown a video with words at the bottom of the screen but were instructed to ignore them-a task that requires exercising control over one's attention. First, by measuring blood glucose (sugar) levels pre- and post-task, it was shown that performing this task (relative to a control task with no attentional instructions) led to a relatively greater depletion of glucose. This general result was obtained for a variety of self-control measures. Most interestingly, another study was conducted in which the same task was performed, but this 
time some subjects ingested a high glucose drink (lemonade) before the test; other subjects were given a placebo drink that contained no sugar, only artificial sweetener. When the subjects were given a subsequent demanding task (a Stroop task), those who had consumed the sugared drink performed better than those who received the placebo control, suggesting that the glucose had "replenished" their ability to do a task with high attentional demands.

These experiments illustrate a possible way of estimating costs, but they also illustrate another concern: the distinction between normal operating costs and capacity costs. An analogy to the power industry is helpful here. Electrical grids that supply cities and states with power must be designed for peak load, not for average load. Thus, examining the grid at some times of the day would suggest that it is over-designed. At peak usage however (hours and seasons), such grids can buckle under the combined drain of, for example, millions of air conditioners. If natural selection has designed nervous systems to cope with similar time-variant demand problems, then we will need to understand how much circuit implementations cost in comparison to one another under several different system conditions, including energy shortage and "peak load."

Yet another kind of cost to consider is opportunity cost. Most people have had the experience of walking or driving the wrong way, in a familiar place, because they had been lost in thought. Different implementations may imply different conflicts among circuits or sensory inputs. To give a simple example, organisms that rely mainly upon a single sense, vision for example, may not be able to afford devoting attention to a single task. Monkeys tend to have quite short attention spans, from the perspective of human researchers, perhaps as a result of an history of selection under predation. With only a single set of eyes, a monkey pays an opportunity cost of increased risk of being eaten if he fixes his eyes only upon the task at hand.

If any of these conjectures-path-dependent local optima or the difficulties of deducing evolutionarily relevant costs-holds, it will be hard to make useful predictions about the cognitive machinery from only the function or algorithm that provides for a decision. This, however, is not necessarily a negative message. We expect progress will be made in time, by appreciating how details matter in organic evolution. Evolutionary biology has made fantastic progress, over the last fifty years, in understanding the evolution of behavior, partly because evolutionary biologists came to appreciate that proximate details (such as how traits are inherited and how sex determination works) have profound effects on ultimate outcomes. It is usually not enough to understand the evolutionary function (how the trait enhances survival or reproduction) in isolation, if we aim to understand the design of behavior. We expect the same principle will hold as we delve more deeply into the structure of cognition. 


\section{The Evolution of Deliberative Decisions}

Many social scientists and philosophers are interested in a seemingly unique human decision-making capacity: deliberative reasoning. By deliberative reasoning, we mean decision processes accessible to consciousness. Sometimes these processes are represented explicitly in human language. It is possible that the process of deliberative reasoning is different from nondeliberative, "unconscious," decision mechanisms. Conscious reasoning is often thought to take more time than automatic mechanisms, but it is also perceived as more flexible. This is a folk-psychological cluster of concepts, so many scientists and philosphers are suspicious of its value, despite the enthusiasm for the distinction on the part of other scientists and philosophers.

However, philosophers of psychology sometimes invoke a gambit known as the simple correspondence thesis (Fodor 2005). This gambit applies to many domains, but is sometimes directed to theory of mind, the mechanisms that allow people to attribute mental states to and predict the behavior of others. Since our theory of mind mechanisms seem to work (i.e., they do better than chance at predicting behavior), they may correspond partially to the real structure of the mind. To the extent that the deliberative/automatic distinction is widespread in human societies, the simple corresponding thesis leads us to entertain it as a scientific concept, but not to commit to it on any evidential basis. Explaining why some, or any, thought is consciously accessible seems worthwhile.

If deliberative reasoning is a valid concept that describes the structure of human cognition, what evolutionary function might it have been selected to serve? There are no dominant hypotheses. We do note four possibilities, none mutually exclusive.

First, deliberative reasoning, because of its often explicit linguistic nature, may be the mind's press secretary (Kurzban, this volume). Explaining one's mental states and motivations to others can be of great value in social life. In order to encode these states as language, they must be made conscious. Press secretaries sometimes lie, of course, but not always.

A second possibility is that deliberative reasoning facilitates verbal encoding which in turn serves collective decision-making functions. Juries must deliberate to reach a verdict. Judges must write closely argued opinions which will be reviewed by appellate courts and perhaps eventually vetted as a correct interpretation of the law. An executive decision maker confers typically with advisors before making important decisions.

Third, the function of deliberative reasoning may be to "tame" automatic reasoning. That is, deliberative reasoning might function to halt and re-fit trained automatic mechanisms. For example, once a musician has learned to play an instrument, many aspects of performance are automatic, requiring little conscious deliberative effort, if any. In fact, some musicians report that deliberative processes interfere with performance. However, if a musician observes 
another musician using a better technique, the musician must halt and retrain the automatic system in order to incorporate this new technique.

A fourth option is that explicit deliberative reasoning is related to the manipulation and transmission of complex, socially transmitted behavior-cultural traditions. For example, explaining to a neophyte how a machine or an institution works may facilitate rapid acquisition of knowledge compared to merely observing examples of the object in action.

\section{Cultural Evolution and the Design of Institutions}

Most of the previous discussion treats humans as any other animal. In a very real sense, we are just another animal. However, like any other animal, we are unique. In our case, there is substantial evidence that humans are unique among mammals in relying heavily on social learning to acquire large, important aspects of our behavior (Richerson and Boyd 2005). Other animals, such as song birds and some apes, clearly have stable socially transmitted traditions (see Fragaszy and Perry 2003). However, in all cases, these traditions are quite simple-few if any are more complex than what could be invented by an individual in its lifetime-and confined to a narrow range of behavioral domains. Humans, in contrast, acquire extraordinarily complex, locally adapted patterns of behavior in nearly every domain of belief and behavior. Humans occupy every environment on the planet, with the same basic tropical-ape physiology. With less genetic variation than that found between different populations of chimpanzee, humans exhibit a greater range of subsistence type and social organization than all the other primates combined.

Formal evolutionary models of social learning mechanisms suggest that social transmission of this sort is favored in variable environments. Above, we explained that learning is favored when organisms experience different environments on timescales that are neither too short (when learning would be pointless) nor too long (when genetic fixation would suffice). Embedded in the middle of the same spectrum of evolutionary outcomes is a broad range of stochastic contexts in which a heavy reliance on social learning is favored (Aoki et al. 2005; Wakano and Aoki 2006). The insight is that environmental change that is autocorrelated favors social learning, because while variation favors learning, the autocorrelation means there is enough time to build locally adapted cumulative traditions, before the next shift in the environment. The Pleistocene climate record exhibits exactly this sort of environmental stochasticity, and this is the period when human brains expanded and archaeological signs of human "culture" began to appear (Richerson et al. 2005).

Much of the adaptive advantage of culture comes from the way it economizes on cognitive effort. If every individual has to acquire the behaviors necessary to cope with a variable environment for themselves, much of what is learned will have to be relearned by every individual in every generation. 
By allowing individuals to imitate other individuals at a much lower cost than learning for oneself, great economies are possible. Accurate imitation also supports the accumulation of innovations to build complex technological and institutional adaptations. The legal code that any competent lawyer can master represents the cumulative wisdom of generations of legal scholarship and practice. No single lawyer, no matter how energetic or brilliant, could do as well. Thus, the population-level properties of culture leverage the costly deliberative decision-making systems. Formal institutions may be largely a product of this process. Cultural evolutionary processes also leverage less costly nondeliberative decision making. If many individuals exercise evolved decision heuristics that are at least accurate on average to bias their acquisition of cultural variants, cultural adaptations will arise without anyone having to invest in costly decision making. As with natural selection, weak biases that are only slightly better than chance at the individual level will act as powerful evolutionary forces when cumulated over many individuals and many generations. Informal institutions may evolve mainly by nondeliberative mechanisms.

The human reliance on social transmission builds complex technology, as well as knowledge that individuals can use to improve their own decision making. However, much of conspicuous cultural variation in our species takes the form of shared rules for behavior. As we said in the introduction, we define institutions as locally stable, widely shared rules that regulate social behavior. While it is possible, and probably true in some cases, that decision mechanisms independent of culture and social learning can stabilize shared patterns of behavior (as in a classic Nash equilibrium), institutions like the grindadráp, Roman law, and even the diversity of systems of exchange and property contain substantial amounts of shared rules that suggest social transmission and evolution. All of the knowledge contained in, for example, complex Australian aboriginal age-grade systems-which specify which men control the marriage options of other men, as well as how men move from one age-grade to the next-requires social transmission of explicit knowledge. This begs the questions of how the detailed structure of individual cognition interacts with human institutions, as well as mechanisms by which institutions themselves evolve, both under the influence of individual decision mechanisms, as well as other higher-level mechanisms.

\section{How Does Individual Decision Making Influence Institutions?}

When Spanish explorers encountered the highly structured and complex Aztec and Inca empires of the Americas, it was almost as if they were encountering aliens. The last common ancestor of the Spaniards and the Native Americans lived deep in the Pleistocene, long prior to the advent of agriculture. In many ways, their languages and cultures could not have been more different, given the length of separation. Nevertheless, the Spaniards discovered 
many similar themes in the organization of American societies, themes they quickly exploited.

Amazed at the diversity of human societies and their institutions, we sometimes overlook the incredible convergences. Despite their long separation and independent evolution of agriculture, political hierarchy, construction, architecture, accounting, exchange, and a number of other institutions, the Europeans and Americans found that a broad set of their assumptions about life in their own complex society applied also, with small modification, to life in the other.

It seems likely that a common set of individual psychological processes tend to structure human societies in a limited number of ways. Consider social exchange. Exchange is a key institutional foundation of human economies. Exchange permits individuals to specialize in productive activities that take advantage of their inherent and acquired characteristics, while allowing these individuals to consume a radically different basket of goods.

Human beings may have an inherent proclivity for barter even with unrelated individuals. Charles Darwin was an astute observer of human beings, as well as of the natural world. When the Beagle reached Tierra del Fuego, at the southern tip of South America, Darwin had an opportunity to interact with the locals. He wrote (Darwin 1845, Chapter X):

Some of the Fuegians plainly showed that they had a fair notion of barter. I gave one man a large nail (a most valuable present) without making any signs for a return; but he immediately picked out two fish, and handed them up on the point of his spear.

Whatever the evolutionary scenario that gives humans widespread prosocial motives such as this, they possibly underwrite similarities in the design of institutions for exchange, the world over. This is not to say that the differences in markets and exchange customs are not significant. However, the fact that the Fuegian, who could not speak a word of English, understood Darwin's gift as an invitation for trade implies that individuals bring a set of characteristically human motives and filters to the table. These motives help structure both explicitly designed institutions as well as institutions that evolve through the nondeliberative action of many individuals. We discussed two interesting cases in which the plausible design of individual decisions, often unconscious, have quite strong effects on social institutions.

Marriage rules illustrate how evolved psychological mechanisms may shape the cultural evolution of institutions. The institution of preferential cousin marriage exists in many societies. In some cases it is thought to function to prevent the kin groups from losing assets through marriage. For example, the institution of patrilateral parallel cousin marriage-men marry their father's brother's daughters - is common in Middle Eastern societies. Many scholars believe that this institution functions, at least in part, to preserve property 
within the patrilineage (Khuri 1970), a view consistent with an equilibrium selection model of institutional evolution. However, if so, preferential brother sister marriage would be an even better institution for preserving such assets. Yet no ethnographically known society supports an institution of brother sister marriage.

The likely reason is that this solution is precluded by the evolved psychology of sexual desire. There is much evidence that people are not sexually attracted to those with whom they had frequent, close social contact when they were growing up, and that if marriages between brothers and sisters were prescribed, they would likely have low fertility, high rates of infidelity, and high divorce rates (Fessler and Navarrete 2004). Moreover, contemplating sexual relations among brothers and sisters elicits strong feelings of disgust. Both mechanisms appear to preclude the evolution of institutionalized brother sister marriage, even though it might be a good solution to the problem of maintenance of property within the family. While there are rare examples of elites who attempted to institutionalize sibling marriage, these are quite rare and were apparently ephemeral.

Another example comes from certain kinds of ritual. In every culture ever studied, religious ceremonies, changes in life stage, and threatening situations such as death or disease are accompanied by culturally specified behavior. This behavior is often "ritualized," meaning that the actions (a) are compulsory, (b) rigidly conform to a script, (c) are divorced from observable goals, (d) exhibit internal repetition, and (e) share common themes of danger and pollution. Boyer and Lienard (2006) argue that commonness of ritualized behavior can be explained in terms of an evolved "precaution system" present in human psychology. This specialized system was favored by natural selection because it allowed individuals to detect potential, but not yet manifest dangers (e.g., such as contamination, disease, or predation). Boyer and Lienard believe that when this system is working it helps people detect and deal with environmental hazards. When it misfires, it gives rise to Obsessive Compulsive Disorder $(\mathrm{OCD})$. Cultural rituals that activate this system are more attention grabbing, more memorable, and more satisfying, and as a result ceremonial routines that involve ritualized behavior tend to spread and persist to a greater extent than ceremonies that do not activate this system.

If either of the above examples is correct, it would constitute a case where the adaptive design of individual decision making has a strong influence on the design of institutions, and therefore on the decisions individuals make within those institutional contexts.

\section{How Do Institutions Evolve?}

However strong unconscious individual forces like attraction to ritualized behavior, many different ritual institutions can and are stabilized in human societies. While the 16th century societies of Europe and the Americas were quite 
alike in many ways, they were also strikingly different, and these differences had important consequences. European societies have had a huge influence on the Americas, while American societies have had little influence on Europeans. Differences in technology and military organization had tremendous consequences. Therefore understanding why societies evolve different institutions, at different rates, is the other side of theoretical coin.

We recognize four mechanisms operating within human societies that may transform and stabilize institutions, including creating institutional diversity.

1. Long-lived organisms such as humans have many repeat interactions with the same individuals. Game theoretic models strongly suggest that, in any sufficiently repeated game, there are a great many stable points.

2. Literature exists on the algorithmic structure of mechanisms of social and cultural learning (Henrich and McElreath 2003; Laland 2004). One powerful mechanism is conformity, preferentially adopting majority behavior (Boyd and Richerson 1985). Conformity can be a highly adaptive learning heuristic, because it exploits the fact that many adaptive processes make locally successful behavior into common behavior. While classic socialpsychological evidence of "conformity" (Asch 1951) does not distinguish between linear (in number of people) forms of social learning and greaterthan-linear influence of majority behavior, there is experimental evidence that people possess a conformist tendency, and that it responds to parameters of the environment as predicted by evolutionary theory (McElreath et al. 2005). While exploiting this statistical feature of human environments, conformity also tends to homogenize groups and stabilize variation between groups (Henrich and Boyd 1998).

3. Different kinds of path dependency can stabilize behavior within groups and variation between groups. Coordination payoffs (I do best when I do what you do) can achieve this, even when one equilibrium is more efficient. However, even in the absence of explicitly coordinated payoffs, the path dependency of complex behavior makes it hard to get from local optima to global optima that would homogenize the population. For example, technology tends to evolve in small improvements, not giant leaps (Richerson and Boyd 2005 review the evidence). This means that local improvements in design space may tend to differentiate further groups that started from different initial designs. The evolution of Chinese and European sailing vessels illustrates this point. Chinese vessels began from rafts made from lashed-together bamboo poles, while European vessels began as dugout canoes. The rafts evolved eventually into hulled, masted vessels without a keel-the weight of the forces was supported more evenly across the hull. European boats, in contrast, built a series of "ribs" up from the dugout canoe core, the keel, supporting the forces with a rigid spine. Starting in different directions, the two traditions of sailing technology evolved quite different paths of innovation. 
4. Once institutions of hierarchy or command and control have evolved, small groups of individuals within larger groups can dictate rapid changes in social organization. In this case, the motivations and decisions of those in command will have big effects on social evolution.

However, even if a single individual initially calls all the shots, there are good reasons to believe that social evolution will not be easily explicable in terms of individual cognition. The reason is that between-group processes may affect the long-term fates of different institutional variants. Provided that some between-group variation in institutions is stable (and the above four mechanisms suggest reasons for the ethnographic and historical observation of stable institutional variation in human societies) and that this variation has effects on the fates of societies, then institutional forms can spread or vanish through processes not cleanly tied to many types of individual decision mechanisms. Furthermore, the precise way in which an institution affects a society's fate, in the ecology of societies, implies design aspects of the institutions that will persist and spread over time. It makes a difference whether societies succeed because they conquer their neighbors or because they survive droughts. In the first case, we might expect existing societies to be good at defense and warfare but not necessarily prepared for environmental crisis; in the second, those differences in institutions spread because of differential conquest. We can think of four useful distinctions to make, along these lines.

1. Social evolution might proceed by differential extinction. If some social arrangements are more likely to survive environmental calamities, these arrangements might increase in frequency among human societies. Here it is a game of society-versus-environment. How information flows through a society, how quickly it can respond to information, and how it mediates and suppresses internal conflicts might all contribute to survival. Polynesian societies faced periodic typhoons that denuded islands, perhaps selecting strongly for institutions of storage and recovery managed by chiefs.

2. Social evolution might proceed by differential growth. Ammerman and Cavalli-Sforza (1984) and Sokal, Oden, and Wilson (1991) have argued that agriculture spread into Europe mainly through the spread of farmers, not the spread of farming. If some societies replace others demographically because of fecundity, this might lead to the spread of social institutions that encourage population growth. Richerson, Boyd, and Bettinger (2001) argue that agriculture, once present in a region, spread partly because numerically superior farmers could usually defeat foragers in contests over territory.

3. Social evolution might proceed by differential conquest, even when groups are of comparable sizes. In his book about the rise of European world powers, The Pursuit of Power (1982), William McNeill argues that competition for control of land and resources between rather small European polities created a ratchet for the development of modern military 
institutions, technologies, and goals of elites, and these fueled the later expansive colonial ambitions of European states. Kelly's (1985) synthetic study of the Nuer conquest of the Dinka suggests that institutions do spread by differential conquest, even in traditional societies without professional militaries.

4. Social evolution might proceed by differential influence. Societies sometimes adopt willingly the social arrangements and beliefs of their neighbors. David Boyd (2001) documents the decision-making process through which the Irakia Awa of Papua New Guinea eventually adopted the economic and ritual institutions of their neighbors, the Fore. The Irakia Awa observed that the Fore were better-off, and they set out to imitate them at the institutional level. These transformations might operate without extinction, replacement, conquest, or coercion. Exactly what makes societies favorable in these comparisons matters, of course. If rates of extraction and consumption are what is driving social evolution, then we should not expect societies to be well-equipped to manage their environments.

These four different mechanisms may imply quite different rates of change, as well, and this may help us evaluate the relative importance of each. Soltis et al. (1995) surveyed New Guinea ethnographic history to estimate the rate at which social competition might spread institutions. They concluded that social complexity would spread very slowly, requiring in the order of many hundreds of years, by this mechanism. Differential extinction by environmental failure certainly interacts with direct group competition, but its rate seems unlikely to be more rapid. While internally caused extinctions are known (Diamond 2004), populations have existed at low densities for much of human history, making it hard to exhaust local resources. Islands, such as Easter Island, are possible exceptions. Differential influence might diffuse innovations rather quickly (Boyd and Richerson 2002) because it is limited by the rate of social comparison rather than the rate of tragedy or violent conflict.

\section{References}

Alexander, D. E. 2002. Nature's Flyers: Birds, Insects, and the Biomechanics of Flight. Baltimore: Johns Hopkins Univ. Press.

Ammerman A. J., and L. L. Cavalli-Sforza. 1984 The Neolithic Transition and the Genetics of Populations in Europe, pp. 109-113. Princeton: Princeton Univ. Press.

Aoki, K., J. Y. Wakano, and M. W. Feldman. 2005. The emergence of social learning in a temporally changing environment: A theoretical model. Curr. Anthro. 46:334-340.

Asch, S. E. 1951. Effects of group pressure upon the modification and distortion of judgment. In: Groups, Leadership and Men, ed. H. Guetzkow. Pittsburgh: Carnegie Press.

Balda, R. P., A. C. Kamil, and P. A. Bednekoff. 1997. Predicting cognitive capacities from natural histories: Examples from four corvid species. Curr. Ornithol. 13:3366. 
Bergert, F. B., and R. M. Nosofsky. 2007. A response-time approach to comparing generalized rational and take-the-best models of decision making. J. Exp. Psychol.: Learn. Mem. Cogn 33(1):107-129.

Boyd, D. J. 2001. Life without pigs: Recent subsistence changes among the Irakia Awa, Papua New Guinea. Hum. Ecol 29(3):259-282.

Boyd, R., and P. J. Richerson. 1985. Culture and the Evolutionary Process. Chicago: Univ of Chicago Press.

Boyd, R., and P. J. Richerson. 2002. Group beneficial norms spread rapidly in a structured population. J. Th. Biol. 215:287-296.

Boyer, P., and P. Leinard. 2006. Why ritualized behavior? Precaution systems and action parsing in developmental, pathological and cultural rituals. Behav. Brain Sci. 29:1-56.

Bröder, A., and S. Schiffer. 2003. "Take The Best" versus simultaneous feature matching: Probabilistic inferences from memory and effects of representation format. $J$. Exp. Psychol.: Gen. 132:277-293.

Cosmides, L., and J. Tooby. 1992. Cognitive adaptations for social exchange. In: The Adapted Mind, ed. J. Barkow, L. Cosmides, and J. Tooby, pp. 163-228. New York: Oxford Univ. Press.

Darwin, C. 1845. Journal of Researches into the Natural History and Geology of the Various Countries Visited by H.M.S. Beagle. London: John Murray. http://darwin-online.org.uk/content/frameset?itemID=F14andviewtype=sideandpag eseq $=1$

Diamond, J. 2004. Collapse: How Societies Choose to Fail or Succeed. New York: Viking Adult.

Dudley, R. 2002. The Biomechanics of Insect Flight: Form, Function, Evolution. Princeton: Princeton Univ. Press.

Emlen, S. T. 1970. Celestial rotation: Its importance in the development of migratory orientation. Science 170:1198-1201.

Fessler, D. M. T., and C. D. Navarrete. 2004. Third-party attitudes toward sibling incest: Evidence for Westermarck's hypotheses. Evol. Hum. Behav. 25:277-294.

Fodor, J. 2005. The Language of Thought. Cambridge, MA: Harvard Univ Press.

Forster, M., and E. Sober. 1994. How to tell when simpler, more unified, or less ad hoc theories will provide more accurate predictions. Brit. J. Philos. Sci. 45:1-35.

Fragaszy, D. M., and S. Perry, eds. 2003. The Biology of Traditions: Models and Evidence. Cambridge: Cambridge Univ. Press.

Gailliot, M. T., R. F. Baumeister, C. N. DeWall et al. 2007. Self-control relies on glucose as a limited energy source: Willpower is more than a metaphor. J. Pers. Soc. Psych. 92(2): 325-336.

Garcia, J., and R. A. Koelling. 1966. Relation of cue to consequence in avoidance learning. Psychon. Sci. 4: 123-124.

Gigerenzer, G., P. M. Todd, and the ABC Research Group. 1999. Simple Heuristics That Make Us Smart. Oxford: Oxford Univ. Press.

Henrich, J., and R. Boyd. 1998. The evolution of conformist transmission and the emergence of between-group differences. Evol. Hum. Behav. 19: 215-242.

Henrich, J., and R. McElreath. 2003. The evolution of cultural evolution. Evol. Anthro. 12:123-135.

Kahneman, D., and Tversky, A. 1979. Prospect theory: An analysis of decision under risk. Econom. 47:263-292.

Kelly, R. C. 1985. The Nuer Conquest: The Structure and Development of an Expansionist System. Ann Arbor: Univ. Mich. Press. 
Khuri, F. I. 1970. Parallel cousin marriage reconsidered: A middle eastern practice that nullifies the effects of marriage on the intensity of family relationships. Man 5:597-618.

Laland, K. N. 2004. Social learning strategies. Learn. Behav. 32(1):4-14.

Land, M. F., and D.-E. Nilsson. 2002. Animal Eyes. Oxford: Oxford Univ. Press.

Lohmann, K. J., C. M. F. Lohmann, L. Ehrhart et al. 2004. Geomagnetic map used in sea turtle navigation. Nature 428: 909-910.

McElreath, R., M. Lubell, P. J. Richerson et al. 2005. Applying evolutionary models to the laboratory study of social learning. Evol. Hum. Behav. 26:483-508.

McNeill W. 1982. The Pursuit of Power: Technology, Armed Force, and Society since A.D. 1000. Chicago: Univ. Chicago Press.

Nilsson, D.-E. 1989. Vision optics and evolution. BioScience 39(5):298-307.

Payne, J. W., J. R. Bettman, and E. J. Johnson. 1993. The Adaptive Decision Maker. Cambridge: Cambridge Univ. Press.

Raby, C. R., D. M. Alexis, A. Dickinson, and N. S. Clayton. 2007. Planning for the future by western scrub-jays. Nature 445:919-921.

Reader, S. M., and K. N. Laland. 2002. Social intelligence, innovation, and enhanced brain size in primates. Proc. Nat. Acad. Sci. 99:4436-4441.

Real, L. A. 1991. Animal choice behavior and the evolution of cognitive architecture. Science 253:980-886.

Richerson, P. J., R. L. Bettinger, and R. Boyd. 2005. Evolution on a restless planet: Were environmental variability and environmental change major drivers of human evolution? In: Handbook of Evolution: Evolution of Living Systems (including Hominids), ed. F. M. Wuketits and F. J. Ayala, vol. 2, pp. 223-242. Weinheim: Wiley-VCH.

Richerson, P. J., and R. Boyd. 2005. Not by Genes Alone. Chicago: Univ. Chicago Press.

Richerson, P. J., R. Boyd, and R. L. Bettinger. 2001. Was agriculture impossible during the Pleistocene but mandatory during the Holocene? A climate change hypothesis. Am. Antiq. 66:387-411.

Sauer, F. 1957. Die Sternenorientierung nächtlich ziehender Grasmücken (Sylvia atricapilla, borinund curruca). Zeitschrift Tierpsychol. 14:29-70.

Sokal R. R., N. L. Oden, and C. Wilson. 1991 Genetic evidence for the spread of agriculture in Europe by demic diffusion. Nature 351:143-145.

Sol, D., R. P. Duncan, T. M. Blackburn, P. Cassey, and L. Lefebvre. 2005. Big brains, enhanced cognition, and response of birds to novel environments. Proc. Nat. Acad. Sci. 102(15):5461-5465.

Soltis, J., R. Boyd, and P. J. Richerson. 1995. Can group-functional behaviors evolve by cultural group selection? An empirical test. Curr. Anthro. 63:473-494.

Tooby, J., and L. Cosmides. 1992. The psychological foundations of culture. In: The Adapted Mind: Evolutionary Psychology and the Generation of Culture, ed. J. Barkow, L. Cosmides, and J. Tooby, pp. 19-136. New York: Oxford Univ. Press.

Wakano, J. Y., and K. Aoki. 2006. A mixed strategy model for the emergence and intensification of social learning in a periodically changing natural environment. Theor. Pop. Biol. 70:486 497. 